\title{
BMJ Open Is pulmonary embolism recurrence linked with the severity of the first event? A French retrospective cohort study
}

\author{
Emile Ferrari (D) , ${ }^{1}$ Etienne Fourrier, ${ }^{1}$ Florian Asarisi, ${ }^{1}$ Nathan Heme, ${ }^{1}$ \\ Nassim Redjimi, ${ }^{1}$ Nathalie Berkane, ${ }^{2}$ Mohamed Labbaoui, ${ }^{1}$ \\ Jean Philippe Breittmayer, ${ }^{1}$ Sok Sithikun Bun, ${ }^{1}$ Pamela Moceri (D) , ${ }^{1}$ Fabien Squara ${ }^{1}$
}

To cite: Ferrari E, Fourrier E, Asarisi F, et al. Is pulmonary embolism recurrence linked with the severity of the first event? A French retrospective cohort study. BMJ Open 2021;11:e050910. doi:10.1136/ bmjopen-2021-050910

- Prepublication history for this paper is available online To view these files, please visit the journal online (http://dx.doi. org/10.1136/bmjopen-2021050910).

Received 04 March 2021 Accepted 17 September 2021

Check for updates

(c) Author(s) (or their employer(s)) 2021. Re-use permitted under CC BY-NC. No commercial re-use. See rights and permissions. Published by BMJ.

${ }^{1}$ Cardiology Department, Centre Hospitalier Universitaire de Nice Hopital Pasteur, Nice, France

${ }^{2}$ Cardiology, Centre Hospitalier de Cannes, Cannes, France

Correspondence to Professor Emile Ferrari; ferrari.e@chu-nice.fr

\section{ABSTRACT}

Objectives Severity of a first pulmonary embolism (PE) is sometimes proposed as a criterion for prolonging anticoagulant treatment. However, little evidence supports this idea. We attempted to determine the connection between severity of first PE and the risk of recurrence. Participants Patients admitted with PE between 2012 and 2018 and for whom anticoagulant treatment had been discontinued were followed. PEs were classified according to the severity into the following two groups: those with associated cardiac involvement (increased cardiac biomarker(s) and/or echocardiographic right ventricular dysfunction) and those with no cardiac involvement which were classified as non-severe. Recurrence-free survivals were estimated using the Kaplan-Meier method and compared using the log-rank test.

Results 417 patients with PEs (186 with cardiac involvement) were followed for at least 1 year after discontinuation of treatment with a mean follow-up of: $3.5 \pm 1.9$ years. 72 patients $(17.3 \%)$ experienced venous thromboembolism recurrence: 24 (5.8\%), 44 (12\%) and $72(28.3 \%)$ respectively, at 1,2 and 5 years. In 63 patients (88\%), recurrence was a PE. Mean time to onset of recurrence was $24.9 \pm 19.9$ months. At 5 years, the recurrence rate is higher when the first $P E$ was associated with cardiac involvement $p=0.043$. In contrast, in patients with provoked $\mathrm{PE}$, the recurrence rate is higher when the first $P E$ event was associated with cardiac involvement: $\mathrm{p}=0.032$. Multivariate analysis demonstrates that $\mathrm{PE}$ severity is an independent factor of recurrence (HR 1.634 (1.015-2.632), $p=0.043$ ).

Conclusion We report for the first time a possible link between a higher recurrence rate and the severity of the first PE. This result which must be confirmed in a dedicated prospective trial could become an important criterion for the duration of anticoagulant therapy after a PE.

Trial registration number NCT04980924.

\section{BACKGROUND}

After the acute event, the choice of the duration of treatment is one of the main problems in the management of a first pulmonary embolism (PE). Currently, provoked versus
Strengths and limitations of this study

Little is known about the severity of pulmonary embolism (PE) and the risk of recurrence.

- This is the first time such a link is investigated.

- This study is a retrospective analysis of prospectively collected data.

- Only symptomatic references were taken into account.

- The exclusion of patients who were long-term anticoagulated may have skewed the results of the nonprovoked PEs subgroup.

non-provoked circumstance is the main criterion used to determine treatment duration. Alongside this main criterion, other factors can also be taken into account such as bleeding risk, sex, blood group, persistence of a venous clot or the end-of-treatment D-dimers level. ${ }^{1-6}$ Some practitioners consider first PE severity as a criterion likely to extend treatment duration. However, very few findings in the literature corroborate this idea.

\section{OBJECTIVE AND METHODS}

Drawing on our regional database, ${ }^{7}$ we made an assessment of the connection between first PE severity and the risk of recurrence of venous thromboembolism (VTE) events. All patients hospitalised for PE from 2012 to 2018 were followed. Only patients whose treatment had been discontinued and for which we had a minimum 12-month follow-up were included. Consequently, patients requiring long-term anticoagulant treatment were excluded, along with patients with active cancer.

In accordance with the literature, ${ }^{8}$ provoked PE was defined as PE which happened within 3 months of a surgery, a trauma, a significant immobility, pregnancy, 


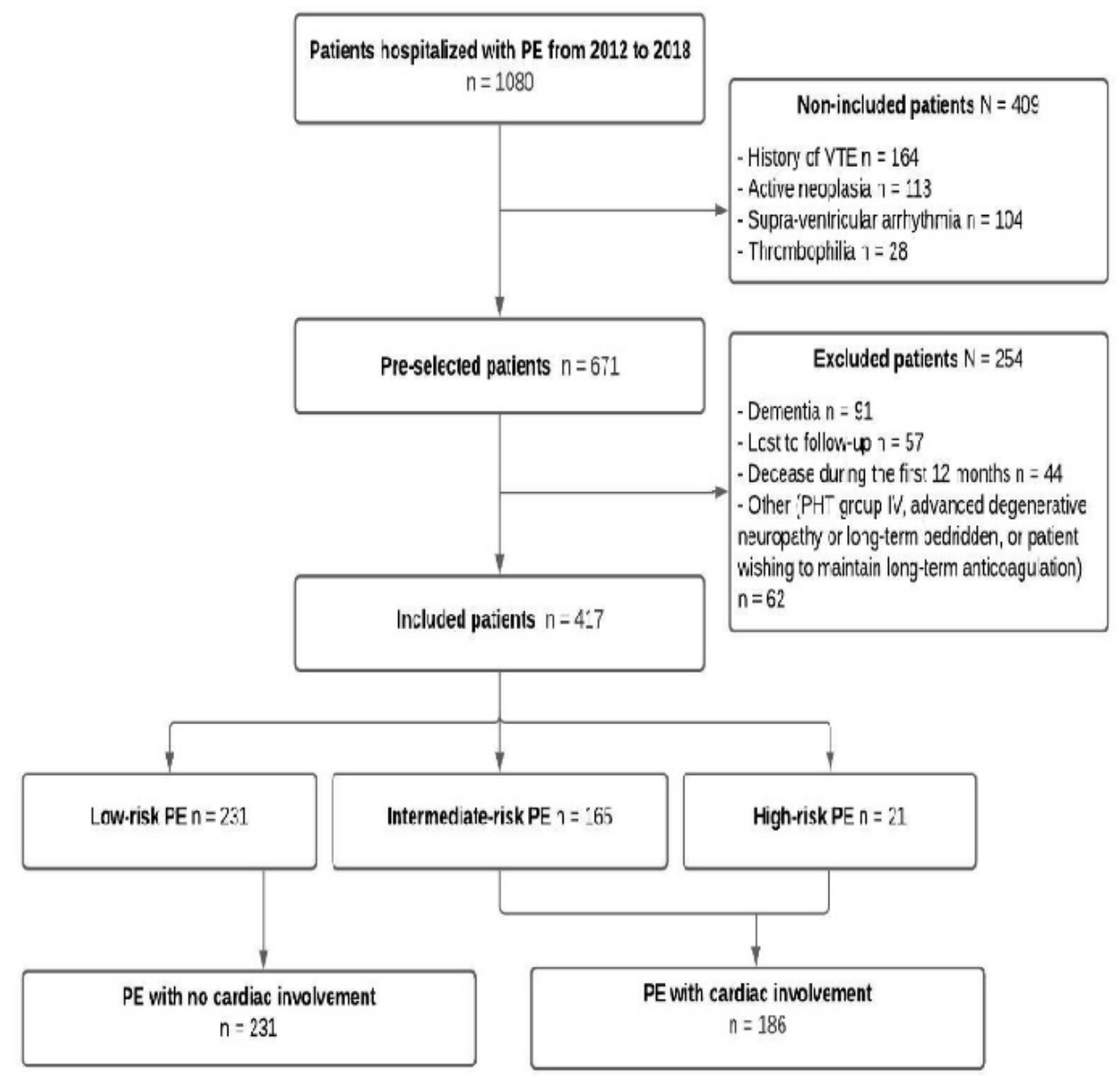

Figure 1 Study flowchart. PE, pulmonary embolism; VTE, venous thromboembolism.

a severe thrombophilia, the use of the combined contraceptive pill, hormone replacement therapy or know thrombogenic treatment. Unprovoked PE was defined as PE for which no transient risk factor or medication was involved. This classification was systematically verified at the 1-month follow-up visit, because new elements, often provided by the family, can highlight unreported aetiologies during the hospitalisation of patients.

In our patients care, a first echocardiography is done on admission, as well as a venous echo-doppler and biomarkers measurement. Biomarkers are repeated at H12, H24 and H48. In this cohort, 99\% of patients were treated with direct oral anticoagulation treatment, namely rivaroxaban or apixaban with a 21-day or 7-day loading dose respectively, then with adapted dosages.

Patients were divided into the following two groups:

1. PE with cardiac involvement: in the presence of haemodynamic instability, increased cardiac biomarkers: Troponin I (Tp) $>70 \mathrm{ng} / \mathrm{L}$ and/or brain natriuretic peptide $(\mathrm{BNP})>100 \mathrm{pg} / \mathrm{mL}$ and/or right ventricular (RV) dysfunction corresponding to intermediate-risk or high-risk PE in the European Society of Cardiology (ESC) classification. ${ }^{9}$ High-sensitivity Tp and BNP were measured with Siemens Centaur and the Alere Triage BNP kit (Beckman Coulter), respectively. The positivity threshold was $70 \mathrm{ng} / \mathrm{L}$ for $\mathrm{Tp}$ and $100 \mathrm{pg} / \mathrm{mL}$ for
BNP. RV dysfunction was defined by echocardiography when a right-to-left ventricular end-diastolic diameter ratio $>0.9$ in the apical four-chamber view or $>0.7$ in the parasternal long-axis view, a tricuspid annular plane systolic excursion $<16 \mathrm{~mm}$ or a tricuspid annular peak systolic velocity (S'-DTI) $<10 \mathrm{~cm} /$ s were observed. It should be noted that these PEs with cardiac involvement combined the high-risk and intermediate-risk classifications of the ESC guidelines. ${ }^{9}$

2. PE with no cardiac involvement when none of the above-mentioned criteria were present corresponding mainly to low-risk PE according to the ESC classification. ${ }^{9}$ These PEs were classified as non-severe in our study.

All chest CT scans were re-read by one radiology expert blinded to the first reading. Special emphasis was placed on eliminating patients with pre-existing pulmonary hypertension as revealed by the patient's medical history or a search for specific signs on the initial scan such as the presence of arterial webs, mural thrombi or a mosaic parenchymal perfusion.

All patients who have had a PE are systematically followed in our department and seen after 1,3 or 6 months then once a year. Recurrences were determined by a new symptomatic venous thrombotic event or by a symptomatic PE confirmed by diagnostic imaging which 


\begin{tabular}{|c|c|c|}
\hline Overall population & $n=417$ & $\%$ \\
\hline Sex F/M, n (\%) & 221 & 53 \\
\hline Age, years (median (IC)) & $65,(63-67)$ & \\
\hline Arterial hypertension, n (\%) & 179 & 43 \\
\hline Obesity, n (\%) & 74 & 18 \\
\hline Dyslipidaemia, n (\%) & 109 & 26 \\
\hline Diabetes, n (\%) & 55 & 13 \\
\hline Smoking, n (\%) & 110 & 26 \\
\hline History of stroke, n (\%) & 26 & 6 \\
\hline Inflammatory disease, n (\%) & 33 & 8 \\
\hline Psychiatric pathology, n (\%) & 83 & 20 \\
\hline Provoked, n (\%) & 212 & 51 \\
\hline Associated DVT, n (\%) & 186 & 45 \\
\hline Proximal DVT & 92 & 22 \\
\hline Distal DVT & 94 & 23 \\
\hline Thrombolysis, n (\%) & 21 & 5 \\
\hline Aspirin treatment & 68 & 16.3 \\
\hline Statin treatment & 42 & 10 \\
\hline Psychotropic medication & 76 & 18.2 \\
\hline $\begin{array}{l}\text { Duration of hospital stay, days (median } \\
\text { (IC)) }\end{array}$ & $5(4-5)$ & \\
\hline $\begin{array}{l}\text { Initial anticoagulation duration, } \\
\text { months (median (IC)) }\end{array}$ & $6(6-6)$ & \\
\hline $\begin{array}{l}\text { Follow-up period, months (median } \\
\text { (IC)) }\end{array}$ & $36(33-40)$ & \\
\hline VTE recurrence, n (\%) & 72 & 18 \\
\hline PE, n (\% of recurrence) & 63 & 88 \\
\hline DVT, n (\% of recurrence) & 9 & 12 \\
\hline $\begin{array}{l}\text { Time to recurrence, in months, } \\
\text { (median, (IC)) }\end{array}$ & $18.5(14-24)$ & \\
\hline
\end{tabular}

DVT, deep vein thrombosis; PE, pulmonary embolism; VTE, venous thromboembolism.

had to show a new clot along with positive D-dimer values. We took into account the age of the patients to construe the D-dimer values.

If patients presented several recurrences during follow-up, only the first was taken into account. A minimum 12-month follow-up was required although a recurrence within this 12-month period was considered as an event. Mean follow-up was $3.5 \pm 1.9$ years. The causes of deaths which happened during follow-up could not be specified.

\section{Patient and public involvement}

This study being a retrospective analysis of prospectively collected data it was not suitable for a partnering with patients, their careers, support networks and the public. Patients were not involved in this study.

\section{Statistical analysis}

All statistical analyses were performed using SPSS software V.20 (Chicago, IL, USA). Quantitative variables were expressed as mean and SD when the distribution was normal, or median and CI when the distribution was not normal. The normal distribution of quantitative variables was assessed using the KolmogorovSmirnov test. Qualitative variables were expressed as counts and percentages. Quantitative variables were compared using the Mann-Whitney U test, and qualitative variables were compared using the $\chi^{2}$ test. Recurrence-free survivals were estimated using the Kaplan-Meier method and compared using the logrank test. Cox proportional hazards regression models were fitted to estimate HRs and 95\% CIs to assess the relationship between baseline clinical characteristics and recurrences. A $p \leq 0.05$ was considered significant.

\section{RESULTS}

Between 2012 and 2018, 1080 patients were hospitalised for PE confirmed by CT scan. One hundred and sixtyfour (164) patients had a history of VTE and had received long-term treatment, 113 had active neoplasia, 104 supraventricular arrhythmia requiring anticoagulant treatment and 91 a cause making follow-up impossible (figure 1). In all, 417 patients with a follow-up exceeding 12 months after discontinuation of their anticoagulation treatment were included. Among these, 231 had presented PE without cardiac involvement and $186 \mathrm{PE}$ with cardiac involvement (165 intermediate-risk PE and 21 high-risk $\mathrm{PE})$. The cohort's initial characteristics are summarised in table 1.

A factor explaining the first PE event was found in 212 $(50.8 \%)$ patients. Associated deep vein thrombosis (DVT) was observed in $186(44.6 \%)$ patients. All provoked PEs were treated for 3 months. All unprovoked PEs were treated for at least 6 months. Mean treatment duration was $5.18 \pm 2.3$ months. Twenty-one patients $(5 \%)$ received thrombolysis. Patient characteristics according to the severity of the initial clinical presentation are shown in table 2. Patients in the PE group with cardiac involvement were more often diabetic: 34/186 (18\%) versus 21/231 $(9 \%)$, more often presented blood clots in the lower limbs: 96/186 (51\%) versus 90/231 (39\%) and averaged longer hospital stays ( $7.3 \pm 4$ days vs $3.7 \pm 3$ days) than patients without cardiac involvement.

Among the entire cohort, 72 patients $(17.3 \%)$ presented VTE recurrence. The VTE recurrence rate after discontinuation of anticoagulation was $5.8 \%(n=24)$ the first year, $12 \%(\mathrm{n}=44)$ at 2 years and $28.3 \%(\mathrm{n}=72)$ at 5 years. In patients experiencing recurrence, $88 \%(\mathrm{n}=63)$ suffered PE and $12 \%(n=9)$ suffered proximal DVT. Mean time to onset of recurrence was $24.9 \pm 19.9$ months. KaplanMeier analysis of the entire cohort shows the survival rate of recurrence-free patients according to initial severity over a 5- year follow-up (figure 2). The recurrence-free survival rate was significantly higher when the first $\mathrm{PE}$ 
Table 2 Initial characteristics of PE groups without and with cardiac involvement

\begin{tabular}{llll} 
& $\begin{array}{l}\text { PE without cardiac involvement, } \\
\mathbf{n = 2 3 1}\end{array}$ & $\begin{array}{l}\text { PE with cardiac involvement, } \\
\mathbf{n = 1 8 6}\end{array}$ & P-value \\
\hline Sex F/M, $\mathrm{n}(\%)$ & $113(48.9)$ & $108(58.1)$ & 0.074 \\
\hline Age, years (mean \pm SD) & $61 \pm 17.2$ & $63 \pm 15.5$ & 0.12 \\
\hline Arterial hypertension, $\mathrm{n}(\%)$ & $90(39)$ & $89(48)$ & 0.068 \\
\hline Obesity, $\mathrm{n}(\%)$ & $43(19)$ & $31(17)$ & 0.622 \\
\hline Dyslipidaemia, $\mathrm{n}(\%)$ & $53(23)$ & $56(30)$ & 0.09 \\
\hline Diabetes, $\mathrm{n}(\%)$ & $21(9)$ & $34(18)$ & 0.006 \\
\hline Smoking, $\mathrm{n}(\%)$ & $72(31)$ & $38(20)$ & 0.012 \\
\hline History of stroke, $\mathrm{n}(\%)$ & $10(4)$ & $16(8.6)$ & 0.073 \\
\hline Inflammatory disease, $\mathrm{n}(\%)$ & $17(7)$ & $16(8.6)$ & 0.187 \\
\hline Psychiatric pathology, $\mathrm{n}(\%)$ & $45(20)$ & $38(20)$ & 0.809 \\
\hline Family history of VTE & $15(6.5)$ & $12(6.5)$ & 0.986 \\
\hline Provoked, $\mathrm{n}$ (\%) & $112(49)$ & $100(54)$ & 0.284 \\
\hline Associated DVT, $\mathrm{n}(\%)$ & $90(39)$ & $96(52)$ & 0.01 \\
\hline Length of hospital stay, days (mean $\pm S D)$ & $4.7 \pm 3$ & $7.3 \pm 4$ & 0.004 \\
\hline Tp (ng/L) & $17(17-17)$ & $298(206-376)$ & 0.0001 \\
\hline BNP (pg/L) & $30(25-34)$ & $293(241-327)$ & 0.0001 \\
\hline RV/LV & $0.62 \pm 0.07$ & $0.96 \pm 0.05$ & 0.01 \\
\hline Duration in months of initial anticoagulation & $5.18 \pm 2.4$ & $5.2 \pm 2.3$ & 0.417
\end{tabular}

BNP, brain natriuretic peptide; DVT, deep vein thrombosis; RV/LV, right-to-left ventricular end-diastolic diameter ratio >0; .9 in the apical fourchamber view.Tp, troponin; VTE, venous thromboembolism.

was non-severe $\mathrm{p}=0.043$. Twelve months after completion of the anticoagulant treatment, the recurrence rate was $7 / 231(3 \%)$, in the non-cardiac involvement group

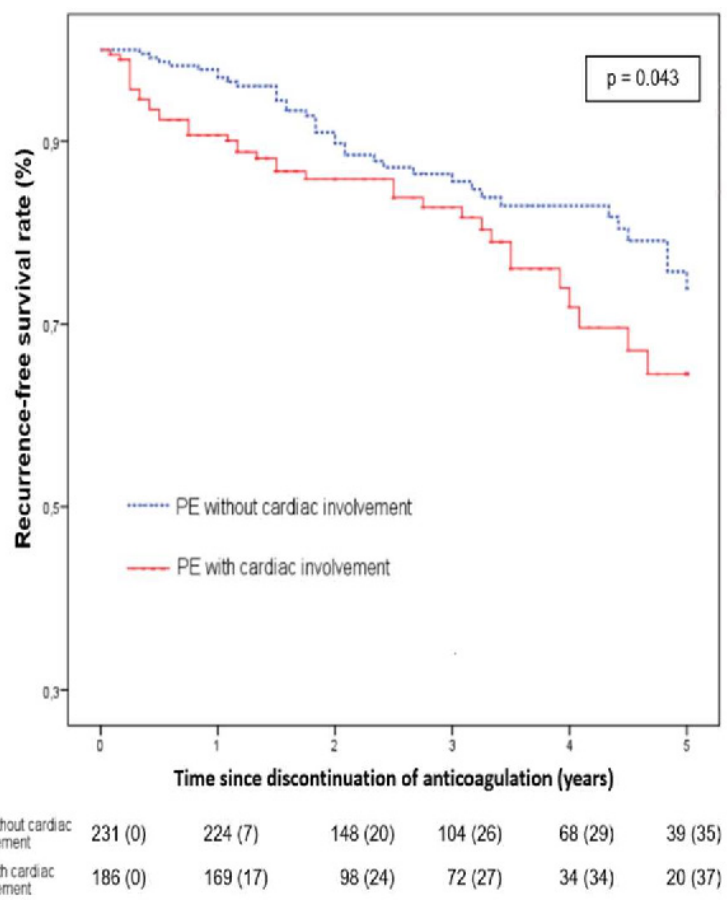

Figure 2 Recurrence-free survival for VTE according to the severity of first PE. PE, pulmonary embolism; VTE, venous thromboembolism. versus $17 / 186(9.1 \%)$, in the cardiac involvement group: $\mathrm{p}=0.007$.

In the multivariate analysis using Cox regression (table 3) including cardiac involvement, gender, family history of VTE, psychotropic medication, unprovoked PE, associated DVT and duration of anticoagulation; cardiac involvement (HR 1.634 (1.015-2.632), $\mathrm{p}=0.043)$ ) and family history of VTE (HR 2.851 (1.422-5.716), p=0.003) were independent risk factors, where as provoked $\mathrm{PE}$ is

Table 3 Multivariate analysis using COX regression for the risk of recurrence

\begin{tabular}{|c|c|c|c|}
\hline Clinical factor & HR & P-value & $95 \% \mathrm{CI}$ \\
\hline Female gender & 1.022 & 0.927 & 0.636 to 1.644 \\
\hline Family history of PE & 2.851 & 0.003 & 1.422 to 5.716 \\
\hline $\begin{array}{l}\text { Psychotropic } \\
\text { medication }\end{array}$ & 1.252 & 0.471 & 0.679 to 2.309 \\
\hline Provoked PE & 0.506 & 0.007 & 0.308 to 0.831 \\
\hline $\begin{array}{l}\text { PE with cardiac } \\
\text { involvement }\end{array}$ & 1.634 & 0.043 & 1.015 to 2.632 \\
\hline Associated DVT & 1.216 & 0.471 & 0.679 to 2.309 \\
\hline $\begin{array}{l}\text { Anticoagulation } \\
\text { duration after PE }\end{array}$ & 1.023857 & 0.196 & 0.988 to 1.061 \\
\hline
\end{tabular}

DVT, deep vein thrombosis; PE, pulmonary embolism; VTE, venous thromboembolism. 


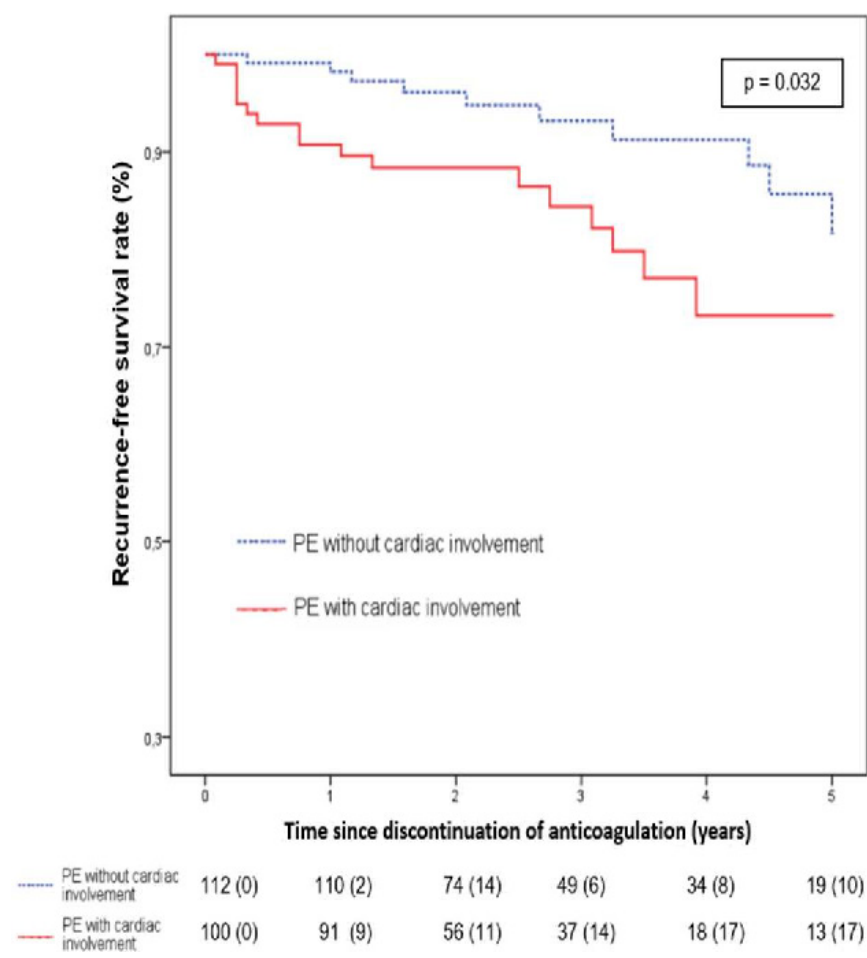

Figure 3 Recurrence-free survival following provoked PE according to the severity of first PE. PE, pulmonary embolism.

associated with less recurrence (HR 0.506 (0.308-0.831), $\mathrm{p}=0.007$ ).

Figure 3 compares the survival rates with no VTE recurrence according to the provoked or unprovoked nature

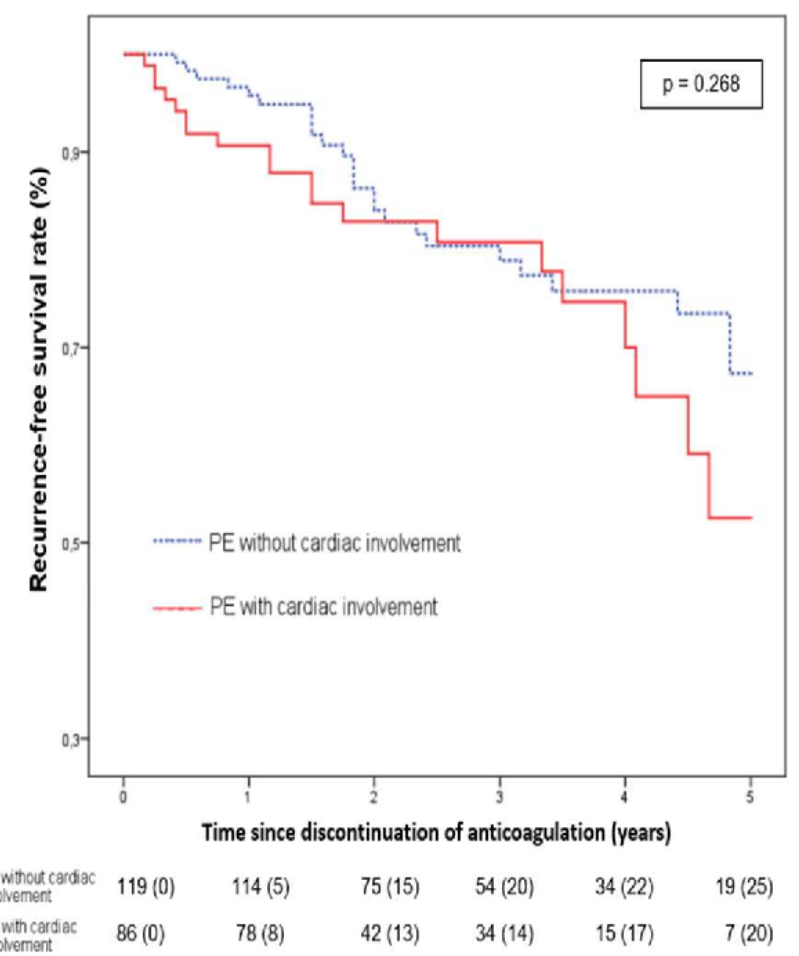

Figure 4 Recurrence-free survival following unprovoked $\mathrm{PE}$ according to the severity of first PE. PE, pulmonary embolism. of the first PE. In the subgroup of patients presenting an unprovoked PE, Kaplan-Meier analysis revealed no difference in recurrence rate according to first PE severity: $\mathrm{p}=0.27$. On the contrary, (figure 4), a higher recurrence rate was noted in the subgroup of patients with a severe provoked PE: $p=0.032$. At 12 months, recurrence rates were, respectively, $2 / 112(1.8 \%)$ when there was no initial cardiac involvement versus 9/100 (9\%) when cardiac involvement was observed; $\mathrm{p}=0.018$.

\section{DISCUSSION}

After the acute phase, the duration of anticoagulation treatment raises one of the major problems in PE management. Some features have been correlated with an added risk of recurrence and are taken into account when choosing a longer treatment. Other criteria are considered although their connection with increased risk of recurrence has not been formally proven. ${ }^{10-12}$ However, to our knowledge, no study has assessed the benefits of pursuing anticoagulant treatment relative to the first PE severity. We thought it would be useful to look for a relationship between the severity of the initial PE and the recurrence rate. In this study including 417 patients followed for a mean of 42 months, the incidence of recurrence was similar to findings described in the literature. In $88 \%$ of cases, recurrence occurred at the same site as the first event. We also observed a well-known added risk of recurrence in cases with unprovoked first PE. We confirm a statistical correlation between the risk of recurrence and the presence of DVT at the time of the first PE. ${ }^{13-16}$

We describe for the first time a higher recurrence rate when the initial PE was severe with a recurrence rate of $9 \%$ versus $3 \%$ and $35.5 \%$ versus $26 \%$, respectively, at 1 and 5 years: $\mathrm{p}=0.043$. Unexpectedly, the correlation between PE severity and the risk of recurrence was stronger when PE was provoked: $p=0.032$. The lack of a relationship in our study between severity and recurrence among unprovoked PE could be explained by the fact that we maintained anticoagulation treatment in patients at higher risk of recurrence and consequently these patients were not included in our analysis. It is also possible that the high rate of spontaneous unprovoked PE recurrences conceals the impact of the severity factor. In the literature, the only data that can come close to our result are that of Grifoni et $a l^{17}$ who reported a higher rate of recurrence when, after hospitalisation for PE, a RV dysfunction was still present at discharge from hospital.

The human physiological coagulation system is believed to protect us against the risk of thrombosis. The formation of venous clots in risky situations is not the rule. When a venous clot occurs, our coagulation-fibrinolysis system is supposed to control the situation by limiting its spread. The formation of a large amount of clots, and hence the occurrence of PE with cardiac involvement, could mean that control by the physiological coagulation system is even more failing. It could also provide additional, hitherto unknown, information on a greater propensity for recurrence. 
In the literature, the recurrence risk of a provoked $\mathrm{PE}$ is deemed to be sufficiently low not to require long-term treatment. Nevertheless, the risk is still much higher than in a control population. The survey of the literature by Iorio $e^{a l^{18}}$ covering 2268 provoked PE with transitory risk shows a mean $0.7 \%$ annual recurrence rate after surgery but a $3.3 \%$ rate for patients as a whole and a $4.2 \%$ annual recurrence rate for non-surgical transitory risk factors. These two latter rates are close to the findings for unprovoked thromboembolic events. Our results indicate that in these provoked PEs, an over-risk of recurrence could be associated with the severity of the initial event. ${ }^{219-21}$

Our study was a retrospective analysis of prospectively collected data. There are possible limitations; we report only symptomatic episodes, potential changes in risk factors over time (eg, obesity, smoking) could not be taken into account. Some known risk factors of recurrence were not considered in the multivariate analysis as high body mass index or high D-dimer level. Our conclusions cannot be applied to patients with cancer or those needing long-term treatment since these patients were excluded from the study. Our results deserve to be confirmed in a dedicated prospective study.

\section{CONCLUSION}

In this cohort study, we highlight a possible link between the severity of a first $\mathrm{PE}$ and the risk of a subsequent recurrence. The provoked status of PE may not shield against a high recurrence rate when the first event was severe. These findings justify a prospective study designed to confirm this relationship which could change the way we determine the duration of anticoagulation treatment after a first PE.

Contributors EFe and EFo wrote the protocol and designed the study. EFe, NR, NB, ML, SSB and PM followed up patients who were all reviewed with a long follow-up. $\mathrm{EF} 0, \mathrm{FA}$ and NH collected the data. JPB and FS did the statistics.

Funding The authors have not declared a specific grant for this research from any funding agency in the public, commercial or not-for-profit sectors.

Competing interests None declared.

Patient and public involvement Patients and/or the public were not involved in the design, or conduct, or reporting, or dissemination plans of this research.

Patient consent for publication Not applicable.

Ethics approval Our study is in accordance with law n78-17 Information, technology and freedom of 6 January 1978 (modified by the new act dated 6 August 2004) and with the EU 2016/679 European Parliament and the 27 April 2016 Council regulation, applicable from 25 May 2018 (GDRP). This is a noninterventional retrospective cohort study.

Provenance and peer review Not commissioned; externally peer reviewed.

Data availability statement All data relevant to the study are included in the article or uploaded as supplementary information. Throught the correspondant author.

Open access This is an open access article distributed in accordance with the Creative Commons Attribution Non Commercial (CC BY-NC 4.0) license, which permits others to distribute, remix, adapt, build upon this work non-commercially, and license their derivative works on different terms, provided the original work is properly cited, appropriate credit is given, any changes made indicated, and the use is non-commercial. See: http://creativecommons.org/licenses/by-nc/4.0/.

\section{ORCID iDs}

Emile Ferrari http://orcid.org/0000-0002-8233-6039

Pamela Moceri http://orcid.org/0000-0002-0741-1609

\section{REFERENCES}

1 Kyrle PA, Minar E, Bialonczyk C, et al. The risk of recurrent venous thromboembolism in men and women. $N$ Engl J Med 2004;350:2558-63.

2 Prandoni P, Noventa F, Ghirarduzzi A, et al. The risk of recurrent venous thromboembolism after discontinuing anticoagulation in patients with acute proximal deep vein thrombosis or pulmonary embolism. A prospective cohort study in 1,626 patients. Haematologica 2007;92:199-205.

3 Linnemann B, Zgouras D, Schindewolf M, et al. Impact of sex and traditional cardiovascular risk factors on the risk of recurrent venous thromboembolism: results from the German MAISTHRO registry. Blood Coagul Fibrinolysis 2008;19:159-65.

4 Baudouy D, Moceri P, Chiche O, et al. B blood group: a strong risk factor for venous thromboembolism recurrence. Thromb Res 2015;136:107-11.

5 Palareti G, Cosmi B, Legnani C, et al. D-Dimer testing to determine the duration of anticoagulation therapy. N Engl J Med 2006;355:1780-9.

6 Eichinger S, Minar E, Bialonczyk C, et al. D-Dimer levels and risk of recurrent venous thromboembolism. JAMA 2003;290:1071-4.

7 Ferrari E, Baudouy M, Cerboni P, et al. Clinical epidemiology of venous thromboembolic disease. Results of a French multicentre registry. Eur Heart J 1997;18:685-91.

8 Kearon C, Ageno W, Cannegieter SC, et al. Categorization of patients as having provoked or unprovoked venous thromboembolism: guidance from the SSC of ISTH. J Thromb Haemost 2016;14:1480-3.

9 Konstantinides SV, Meyer G, Becattini C, et al. 2019 ESC guidelines for the diagnosis and management of acute pulmonary embolism developed in collaboration with the European respiratory Society (ERS). Eur Heart J 2020;41:543-603.

10 Kearon C, lorio A, Palareti G, et al. Risk of recurrent venous thromboembolism after stopping treatment in cohort studies: recommendation for acceptable rates and standardized reporting. $J$ Thromb Haemost 2010;8:2313-5.

11 Tromeur C, Sanchez O, Presles E, et al. Risk factors for recurrent venous thromboembolism after unprovoked pulmonary embolism: the PADIS-PE randomised trial. Eur Respir J 2018;51:1701202.

12 Cohen AT, Gitt AK, Bauersachs R, et al. The management of acute venous thromboembolism in clinical practice. results from the European prefer in VTe registry. Thromb Haemost 2017;117:1326-37.

13 Khan F, Rahman A, Carrier M, et al. Long term risk of symptomatic recurrent venous thromboembolism after discontinuation of anticoagulant treatment for first unprovoked venous thromboembolism event: systematic review and meta-analysis. BMJ 2019;366:14363.

14 Martinez C, Cohen AT, Bamber L, et al. Epidemiology of first and recurrent venous thromboembolism: a population-based cohort study in patients without active cancer. Thromb Haemost 2014;112:255-63.

15 Albertsen IE, Nielsen PB, Søgaard M, et al. Risk of recurrent venous thromboembolism: a Danish nationwide cohort study. Am J Med 2018;131:1067-74.

16 Baglin T, Douketis J, Tosetto A, et al. Does the clinical presentation and extent of venous thrombosis predict likelihood and type of recurrence? A patient-level meta-analysis. J Thromb Haemost 2010;8:2436-42.

17 Grifoni S, Vanni S, Magazzini S, et al. Association of persistent right ventricular dysfunction at hospital discharge after acute pulmonary embolism with recurrent thromboembolic events. Arch Intern Med 2006;166:2151-6.

18 Iorio A, Kearon C, Filippucci E, et al. Risk of recurrence after a first episode of symptomatic venous thromboembolism provoked by a transient risk factor: a systematic review. Arch Intern Med 2010;170:1710-6.

19 Prins $M H$, Lensing AWA, Prandoni $P$, et al. Risk of recurrent venous thromboembolism according to baseline risk factor profiles. Blood Adv 2018;2:788-96.

20 Ensor J, Riley RD, Moore D, et al. Systematic review of prognostic models for recurrent venous thromboembolism (VTE) post-treatment of first unprovoked VTE. BMJ Open 2016;6:e011190.

21 Bikdeli B, Jimenez D, Hawkins M, et al. Rationale, design and methodology of the computerized registry of patients with venous thromboembolism (RIETE). Thromb Haemost 2018;118:214-24. 